\title{
(S)-2-Heptanol, the alarm pheromone of the stingless bee Melipona solani (Hymenoptera, Meliponini)
}

\author{
David Alavez-Rosas ${ }^{1,2}$, Daniel SÁnChez-GuilléN ${ }^{1}$, Edi A. Malo ${ }^{1}$, \\ Leopoldo CRUZ-LÓPEz ${ }^{1}$
}

\footnotetext{
${ }^{1}$ El Colegio de la Frontera Sur, Carretera Antiguo Aeropuerto Km. 2.5, AP 36, CP 30700, Tapachula, Chiapas, Mexico ${ }^{2}$ Instituto de Biociencias, Universidad Autónoma de Chiapas, Blvd. Príncipe Akishino S/N, Solidaridad 2000, CP 30798, Tapachula, Chiapas, Mexico
}

Received 20 June 2018 - Revised 13 February 2019 - Accepted 5 March 2019

\begin{abstract}
Timely defence response is critical in any highly social bee species. Chemical signalling is closely linked to this behaviour, and several pheromones have been discovered. In this work, we identified the pheromone of the stingless bee Melipona solani and evaluated the electrophysiological and behavioural response of the bee to the identified compound. We determined that the mandibular glands serve as the reservoir of the alarm pheromone. Because enantiomeric recognition has been scarcely examined, we performed bioassays and electroantennographic (EAG) studies to determine the role of chirality in pheromone recognition. We found that (S)-2-heptanol was the active compound involved in the alarm response of this species. Although we did not find (R)-2-heptanol in the mandibular gland extracts, bees responded to it in a similar way to the (S)-isomer and to a racemic mixture. The behavioural response of $M$. solani was flight, different from other Melipona species behaviour. We discuss these findings in an evolutionary and ecological framework.
\end{abstract}

\section{Alarm pheromone / Defence / Stingless bees / Optical isomerism / CG-MS / EAG}

\section{INTRODUCTION}

Stingless bees (Hymenoptera, Apidae, Meliponini) are the most diverse group of all eusocial bees (Meléndez-Ramirez et al. 2013) comprising approximately 500 species in more than 36 genera (Ascher and Pickering 2017). They occur in perennial colonies in tropical and subtropical climates, thus, like honeybees, stingless bees have developed highly complex social interactions (Amano et al. 2000; Michener 2007). For instance, the queen maintains colony cohesion by influenc-

Electronic supplementary material The online version of this article (https://doi.org/10.1007/s13592-019-00639-2) contains supplementary material, which is available to authorized users.

Corresponding author: L. Cruz-López, lcruz@ecosur.mx

Manuscript editor: Cedric Alaux ing the behaviour and physiology of workers, which in turn are responsible for all tasks inside and outside of the colony (Gracioli-Vitti et al. 2004; Michener 2013). Reproductive males serve only to disperse genes and reduce the effect of inbreeding (Cameron et al. 2004).

Stingless bee chemical signalling through pheromones is crucial in most of the social interactions that allow the colony to endure as a unit, to reproduce and to overcome threats from predators and parasites. In this way, alarm pheromones are a key attribute that enables the colony to build a defensive front against potential attackers by recruiting guards towards the intruder (Wyatt 2003a).

A typical defensive behaviour against attackers observed in stingless bees may include attraction, landing, buzzing, biting and zigzag flights (Johnson and Wiemer 1982; Johnson et al. 1985; CruzLópez et al. 2005; Schorkopf et al. 2009; 
Leonhardt 2017). Depending on the context, alarm pheromones could evoke fight or flight behaviour, i.e. alerted workers might engage in physical interaction with the intruder that could end in death, or they might enter the colony and sometimes build a "wall" to close the entrance and prevent the entry of potential attackers (Wyatt 2003b; Schorkopf 2016). Alarm pheromones are released mainly from mandibular glands (Smith and Roubik 1983; Cruz-López et al. 2005; Schorkopf et al. 2009; Leonhardt 2017). They often comprise a mixture of 2-alcohols, 2-ketones and esters [e.g. 2-nonanol and 2-heptanol for Trigona silvestriana (Johnson et al. 1985); 2-heptanol, 2undecanol, 2-tridecanol, 2-heptanone, 2undecanone, 2-tridecanone for T. mexicana and T. pectoralis (Luby et al. 1973); nerol for T. fulviventris (Johnson and Wiemer 1982); 2heptanol, 2-tridecanone and benzaldehyde for T. spinipes; 2-heptanol and nonanal for Scaptotrigona depilis (Schorkopf et al. 2009); 2heptanone and 2-nonanone for Oxytrigona mediorufa (Cruz-López et al. 2007); geraniol and farnesyl acetate for Melipona beecheii (Cruz-López et al. 2005)].

Insects employ chiral pheromones to enrich their communication systems and also to secure greater specificity in perception. This is a strong adaptive advantage for the insect (Mori 1998). Pheromonebased communication is heavily dependent on the stereochemistry of pheromones (Mori 2014). Bees are not an exception; chiral pheromones are used by species of bees in chemical defence [e.g. T. spinipes and Scaptotrigona depilis secreted (S)-(+)-2heptanol by mandibular glands and elicited an attack behaviour in conspecifics (Schorkopf et al. 2009)], male attraction [e.g. females of the solitary bee Colletes cunicularius produce (S)-(+)-linalool to attract males (Borg-Karlson et al. 2003)] and for colony maintenance [e.g. both enantiomers of (S,E)-9-hydroxydec-2-enoic acid, a component of the mandibular gland secretion of the Apis mellifera, are required for optimal formation and maintenance of the retinue response (Slessor et al. 1990)].

In Mexico, stingless bees are ecologically, economically and culturally important. Melipona solani (Hymenoptera, Apidae, Meliponini) is of special interest in the southeast region because of their use in meliponiculture and crop pollination (Ayala et al.
2013). A previous study reported that 2-heptanol was present in head extracts of M. solani (AlavezRosas et al. 2017). Hence, the objective of our study was to elucidate the structure of the alarm pheromone of M. solani, and we tested antennal and behavioural responses of $M$. solani to the compound. The following questions were asked. Do M. solani workers release 2-heptanol as alarm pheromone? Are the mandibular glands the source of this compound? What enantiomer is produced by bees? How do stingless bees respond electrophysiologically and behaviourally to the alarm pheromone?

\section{METHODS AND MATERIALS}

InsectsFour colonies of $M$. solani similar in strength (with a functional physogastric queen, approximately 2500 adults, $8-10$ brood combs, honey reserves of about $1.5 \mathrm{~L}$ and 10 pots full of pollen) and overall health (free of fungi and parasites, and with a good resin accumulation) were used. The experiments were carried out at the campus of El Colegio de la Frontera Sur, in Tapachula, Chiapas, Mexico, from March to September 2016 and January to May 2017.

ChemicalsAll chemicals were purchased from Sigma Aldrich, Toluca, Mexico. (R)-2-heptanol, (S)-2heptanol, racemic-2-heptanol [(R+S)-2-heptanol] all of them had $>98 \%$ of purity, and the enantiomers had $97 \%$ enantiomeric excess (ee). Decane, 4dimethylaminopyridine, pyridine and acetyl chloride had $>98 \%$ purity. Hexane was HPLC-grade. The purity of compounds was checked by GC-FID.

Bee trainingFor field bioassays, bees were trained to collect 2.5 M sucrose solution ad libitum from an artificial feeder consisting of a $10-\mathrm{cm}$ diameter Petri dish containing a cotton ball soaked with the sucrose solution. To investigate the effect of distance, the feeder was placed at either $30 \mathrm{~m}$ or $300 \mathrm{~m}$ southwest of the colonies.

\subsection{Collection of compounds of the alarm pheromone released by workers}

To stimulate workers to release alarm pheromones, they were individually introduced into a $10-\mathrm{mL}$ glass vial capped with foil, which 
was hand shaken for $1 \mathrm{~min}$. Volatile compounds were collected using the solid phase micro extraction (SPME) technique by introducing a poly-dimethylsiloxane fibre (SUPELCO, Deisenhofen, Germany) for 2 min after the shaking (Rochat et al. 2000). A second identical vial with no bee served as a control. This experiment was conducted five times with different bees.

\subsection{Sample preparation}

Complete head extractBees were frozen at $-20^{\circ} \mathrm{C}$ before analysis. The head of 4 foragers were dissected and macerated in $1 \mathrm{~mL}$ of hexane. The macerates were then concentrated to $400 \mu \mathrm{L}$ using a gentle stream of dry $\mathrm{N}_{2}$ and stored at $-20^{\circ} \mathrm{C}$ until analysis.

Mandibular gland extractsGland extracts were prepared by dissecting the mandibular glands from the head of 4 foragers. The compounds were extracted with $1 \mathrm{~mL}$ of hexane and were concentrated with dry $\mathrm{N}_{2}$ to $400 \mu \mathrm{L}$ and stored at $-20^{\circ} \mathrm{C}$ until analysis.

Mandibular gland (solid injection)Mandibular glands were carefully dissected from 2 foragers. The glands were inserted into a quartz microvials and introduced into a GC-MS using a Varian ChromatoProbe sample introduction device.

\subsection{Chemical identification}

All volatiles and extracts were analysed on a GC-MS Varian Star model CP-3800 GC (Palo Alto, CA, USA). A DB-5-fused silica capillary column $(30 \mathrm{~m} \times 0.25 \mathrm{~mm}$ ID) was temperature programmed from $50{ }^{\circ} \mathrm{C}$ (held for $2 \mathrm{~min}$ ) to $280{ }^{\circ} \mathrm{C}$ at $15{ }^{\circ} \mathrm{C} \min ^{-1}$, held at $280{ }^{\circ} \mathrm{C}$ for $10 \mathrm{~min}$. The temperature of the injector was held at $250{ }^{\circ} \mathrm{C}$. The $\mathrm{GC}$ was coupled to a Varian Saturn 2200 mass spectrometer and integrated data system. Ionization was carried out by electron impact (EI) at $70 \mathrm{eV}, 250{ }^{\circ} \mathrm{C}$. Identification was confirmed by comparing retention indexes and mass spectra with those of synthetic standards.

\subsection{Enantiomeric identification}

A GC-MS Shimadzu GC-2010 plus, TripleQuadrupole Mass Spectrometer TQ8040 (Columbia, Maryland, USA) equipped with a $30-\mathrm{m}$ heptakis-(2,3-di-O-methyl-6-O-t-butyldimethylsilyl)- $\beta$-cyclodextrin chiral column, was used to determine which enantiomer bees produced. 2heptyl acetates were separated isothermally at $60^{\circ} \mathrm{C}$.

The result of comparing natural extract with racemic 2-heptanol was not significant because the isomers did not separate in the column. Thus, a derivatization reaction (esterification of secondary alcohols) was necessary.

\subsection{Derivatization procedure}

Secondary alcohols ((R+S)-2-heptanol, (R)-2heptanol, (S)-2-heptanol) were derivatised and compared with the derivatised extract from the head of four workers. Esters were synthesized using the methodology used by Strohalm et al. (2007).

\subsection{Quantification of (S)-2-heptanol}

The amount of (S)-2-heptanol produced by bees was calculated using an internal standard method. A calibration curve was constructed with three concentrations $(20,40$ and $80 \mathrm{ng} / \mu \mathrm{L})$ of (S)2-heptanol, using decane as the internal standard. Three replicates per concentration were done. The head of two bees were macerated in hexane; the solution was decanted and concentrated to $50 \mu \mathrm{L}$, using $10 \mathrm{ng} / \mu \mathrm{L}$ of decane as the internal standard. The extract was analysed by GC-MS, the area of both (S)-2-heptanol and decane were measured, and the concentration was calculated with the calibration curve. Three replicates of each were injected extract with internal standard.

\subsection{Electroantennography}

Foragers from four colonies were sampled and their antennae were carefully removed. EAG experiments were carried out following the procedure of Malo et al. (2004). Four treatments (head extract, (R+S)-2-heptanol, (R)-2-heptanol and (S)-2-heptanol) with four concentrations $(0.1$, $0.5,1$ and 2 bee equivalents) were prepared. The 
treatments were selected by randomised, and the evaluation of concentrations was from lower to higher. We did not complete one replicate with one antenna because the lifetime of the dissected antennae permitted to test only three treatments with their four concentrations (in other words, 12 stimuli). For this reason, we used the other antenna of the foragers. Antennal responses to solvent (hexane, used as the control) were subtracted from response to treatments. Thirty replicates per treatment were conducted (a total of 480 stimuli were performed, belonging to four treatments with four concentrations $\times 30$ replicates). A total of 20 foragers were used.

\subsection{Field bioassays}

Bioassays at the nest entranceResponse of guards to mandibular gland extract and 2-heptanol isomers was measured by the evaluation of the behavioural response of $M$. solani workers to different concentrations $(0.01,0.1,1$ and 10 bee equivalents) of mandibular gland extract $(\mathrm{R}+\mathrm{S})$ 2-heptanol, (R)-2-heptanol, (S)-2-heptanol and hexane (control). The tests were carried out with four colonies of $M$. solani using the protocols similar to Cruz-López et al. (2005). The number of bees biting the ball, flying away from the nest or hiding in the nest was recorded for $1 \mathrm{~min}$ when it was held $5 \mathrm{~cm}$ below the nest entrance. Extract, secondary alcohols and controls were tested in random order between 7:00 and 11:30 hour local time, with 10-min intervals between stimuli to allow the colony to calm down.

Bioassays at artificial feeders The effect of mandibular gland extracts and of individual isomers of 2-heptanol on bees visiting a feeder was tested. These experiments were conducted at 30 and $300 \mathrm{~m}$ from the nest. The protocol was similar to that used for Scaptotrigona aff. depilis (Schorkopf et al. 2009). Bees were trained to visit an artificial feeder at either of the two distances from the colony. The concentrations $0.01,0.1,1$ and 10 bee equivalents were tested at $30 \mathrm{~m}$, and 0.1 and 1 bee equivalents were tested at $300 \mathrm{~m}$. The gland extract, (R+S)-2-heptanol, (R)-2-heptanol and (S)2-heptanol and hexane (control) were applied on filter paper $\left(1 \mathrm{~cm}^{2}\right)$ fixed over the feeder. The percentage of bees leaving the feeder after application of a test substance was evaluated statistically.

Paired-choice bioassays in artificial feedersTo determine whether 2-heptanol has a repellent effect on bees in the forage context, a paired-choice bioassay was performed with feeding sites marked with 1 bee equivalent of 2-heptanol. The bees had to choose between two artificial feeders. One of them was the marked feeder (baited with mandibular extract or $(\mathrm{R}+\mathrm{S})$-2-heptanol or (R)-2-heptanol or (S)-2-heptanol at the beginning of the experiment) and the other was a clean feeder (same amount of pure hexane). The setup was mounted at the training site $(30 \mathrm{~m}$ southwest of the nest) and a few drops of 2.5-M sucrose solution were injected into the nest entrances with the intention of attracting the foragers to the feeders. The number of bees that landed and extended their proboscides into the sugar solution on either the marked feeder or the clean feeder was recorded during $15 \mathrm{~min}$. All bees were marked and captured on their first visit to one of the feeders (to avoid testing individual bees more than once). Only those bees captured during a given experiment and not already marked in preceding experiments were included in the analysis. Only the bees landing, while no other bees were, at or near the feeders were counted to avoid the effects of visual or other unwanted signals provided by such bees. At the end of the respective experiment, the bees were released. Due to the high volatility of 2-heptanol (almost $86 \%$ evaporates in $1 \mathrm{~min}$, Online resource 4), the treatment was applied in the feeder every minute to ensure that the compound was present in all bee choices. The two feeders were $30 \mathrm{~cm}$ apart, and their position was switched every $5 \mathrm{~min}$ to avoid side bias. To ensure that bees were evenly distributed, a control experiment was performed between two identical clean feeders (only with sucrose solution and without markings) following the same procedure as described above. The feeders used for the bioassays were the same as those used for training (see above). Ten replicates were carried out per bioassay.

\subsection{Statistical analyses}

Statistical analyses were carried out using the $\mathrm{R}$ software (R Core Team 2016). All data were non- 
parametrical. EAG data was analysed with the Kruskal-Wallis test followed by the Dunn test. Behavioural response of bees leaving the feeding site and paired-choice bioassay data were analysed with the Kruskal-Wallis test. Data of bioassays at the nest entrance were not analysed statistically but were detailed only as bar plots because, in most cases, the bees retreated to the colony and we were not be able to assure that bees were tested only once in this experiment.

\section{RESULTS}

When the M. solani worker was introduced into a vial and mechanically irritated (shaken the vial), it released 2-heptanol together with minor compounds mainly from the labial glands and cuticle (Figure 1a). In the control experiments, no compounds were found. Chemical analyses of complete head extract shows the presence of 2-heptanol, with larger compounds belonging to labial gland and insect cuticle (Figure 1b). Solid injection of mandibular gland and mandibular gland hexane extract showed that 2-heptanol was present in these glands together with compounds from the rest of the cuticle (Figure $1 \mathrm{c}-\mathrm{d}$ ); most were previously reported hydrocarbons (AlavezRosas et al. 2017).

The analysis performed in the chiral column showed that (S)-2-heptanol was the only enantiomer produced by $M$. solani workers (Online resource 1). This phenomenon was not observed in other stingless bees, in which a mixture of compounds was found. The quantity of 2heptanol produced by one bee was $436 \pm 85 \mathrm{ng}$ (mean $\pm \mathrm{SE}$ ), and this amount was taken as 1 bee equivalent in subsequent experiments.

We found that antennal response increases as the treatment concentration (mandibular extract or 2-heptanol) increased. There are no differences in the intensity $(\mathrm{mV})$ of antennal responses between isomers. The racemic mixture, the (R)-isomer and the (S)-isomer elicited the same antennal response as mandibular gland extract (Figure 2). The EAG experiments were useful to determine that antennal response depends on the treatment concentration.

In the bioassays at the nest entrance, bees retreat to the colony most of the time, only a few bees bit the ball or flew away from the nest (Online resource 2). Generally, bees did not fight; rather, they flew away from the source of the

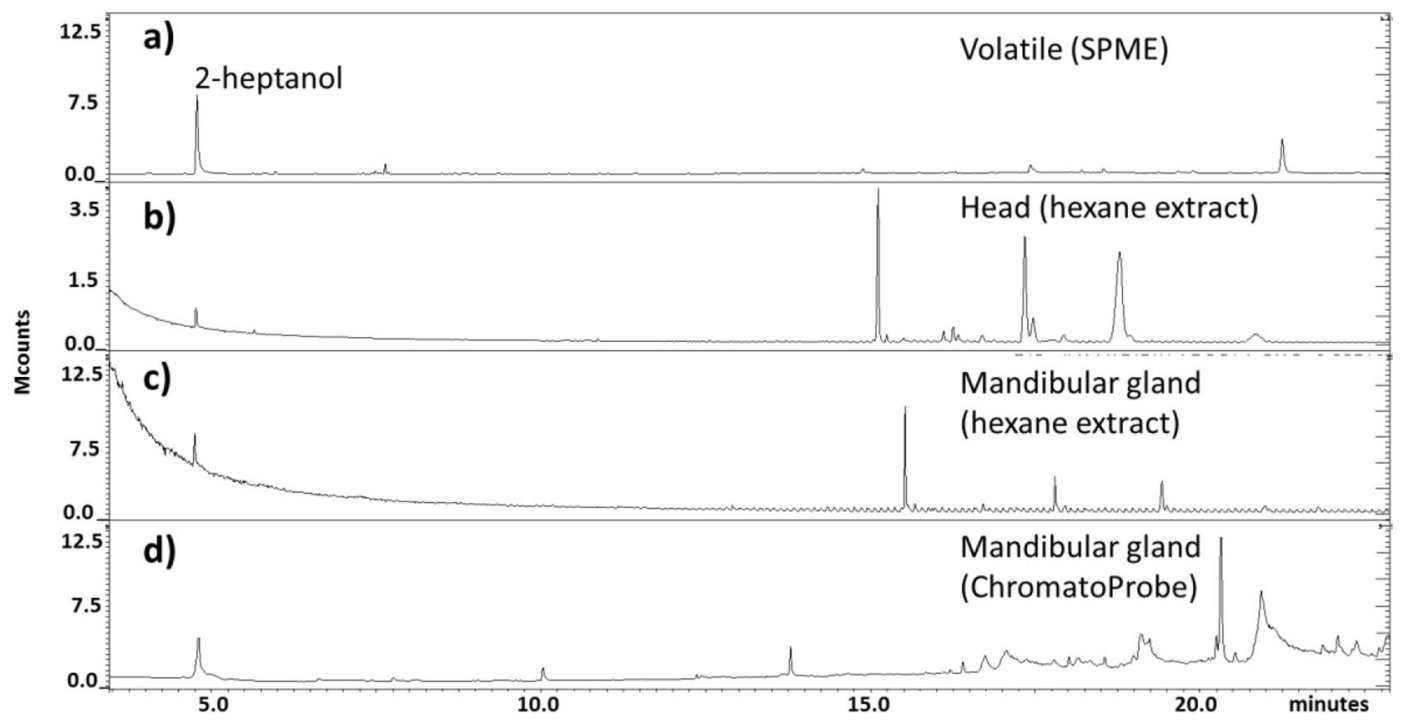

Figure 1. Chromatographic analyses of compounds from M. solani a SPME of volatiles of one worker in a vial, no labelled peaks belong to labial gland. b Head extract from four workers in hexane, no labelled peaks belong to labial gland. c Hexane extract of mandibular glands, no labelled peaks belong to cuticle. $\mathbf{d}$ ChromatoProbe injection of mandibular glands; unlabelled peaks belong to cuticle. 


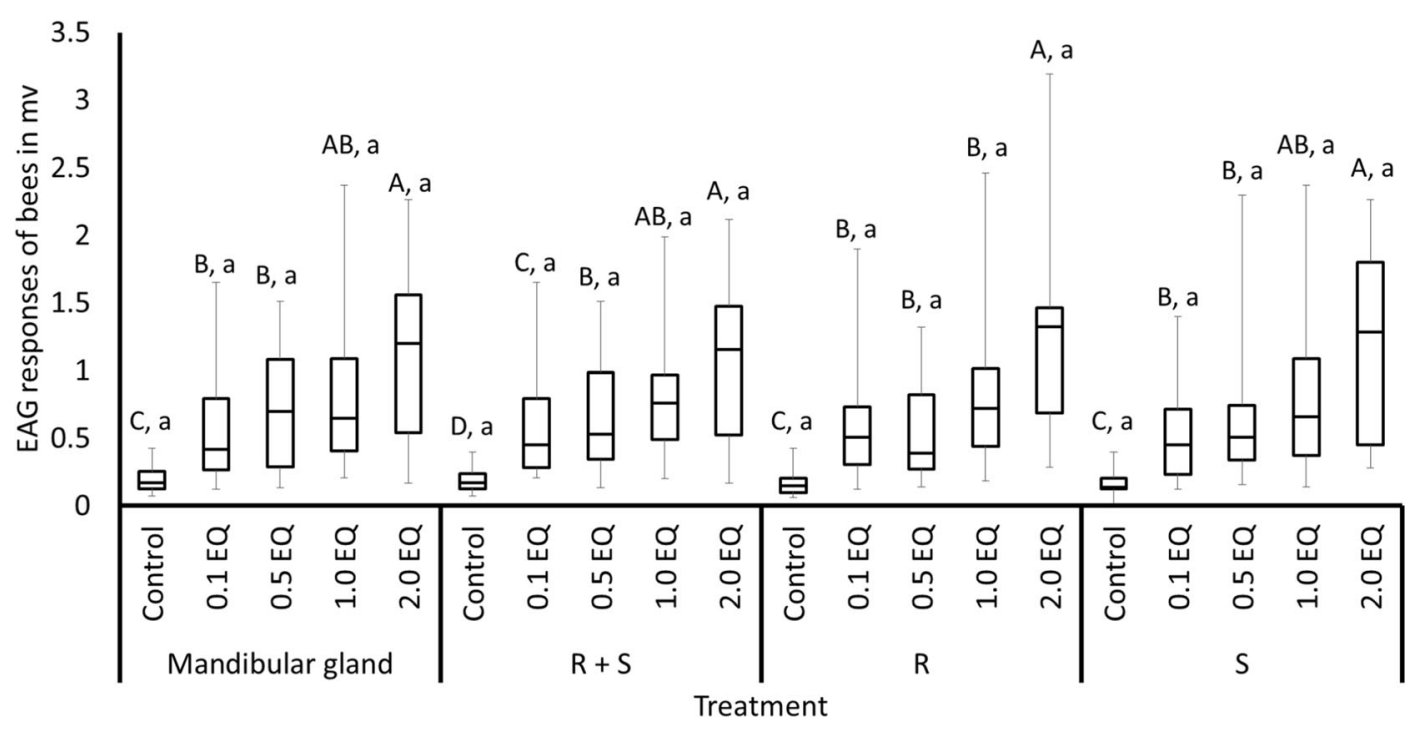

Figure 2. Electroantennographic responses of Melipona solani workers at different concentration of mandibular extract and synthetic secondary alcohols. Control: (Kruskal-Wallis $H=2.26, d f=3, P=0.52$ ). $0.1 E Q$ : (KruskalWallis $H=0.36, d f=3, P=0.95$ ). $0.5 E Q$ : (Kruskal-Wallis $H=1.08, d f=3, P=0.78$ ). $1 E Q$ : (Kruskal-Wallis $H=0.49, d f=3, P=0.92) .2 E Q:$ (Kruskal-Wallis $H=0.59, d f=3, P=0.90)$. Mandibular gland: (Kruskal-Wallis $H=42.16, d f=3, P<0.001)$. $(R+S)$ : (Kruskal-Wallis $H=45.65, d f=3, P<0.001)$. $(R)$ : (Kruskal-Wallis $H=$ 48.85, $d f=3, P<0.001$ ). $(S)$ : (Kruskal-Wallis $H=44.72$, $d f=3, P<0.001$ ). $N=35$ replicates per concentration. (***P $<0.001, * * P<0.01, * P<0.05, N S$ not significant).

alarm pheromone, commonly going back into the nest. Bees responded in the same way to both isomers and to the racemic mixtures and mandibular extract.

Because the bioassays in the entrance of the nest suggested no-fight behaviour, flight behaviour was assessed at feeding sites. Different concentrations were tested to offer the bees a wide range of odour perception. In field bioassays, we aimed to measure a wider range of concentrations to identify possible situations in which a bee could be found in nature. At $30 \mathrm{~m}$, only the concentration of 1 bee equivalent of mandibular gland extract elicited a flight response (Kruskal-Wallis $H=6.74, d f=1, P<0.01)$. For (R)-2-heptanol, a response was observed when 0.1 bee equivalent of treatment was applied (Kruskal-Wallis $H=4.06$, $d f=1, P<0.05)$. In contrast, the racemic mixture and (S)-2-heptanol elicited flight behaviour at all the concentrations except 10 bee equivalents (Figure 3). It is possible that the bee antennae reach a saturation level, and for that reason, no alarm behaviour has been observed in bioassays at 10 bee equivalents. At $300 \mathrm{~m}$, only two concentrations were evaluated $(0.1$ and 1 bee equivalent). At this distance, behavioural response elicited by treatments was apparently enhanced. All treatments at any concentration, except (R)-2-heptanol at 0.1 bee equivalents, elicited alarm behaviour in bees (Online resource 3).

For paired-choice bioassays, it was necessary to determine the release rate of 2-heptanol. One minute after the application of $436 \mathrm{ng}\left(30^{\circ} \mathrm{C}, 80 \%\right.$ $\mathrm{RH})$, the amount of 2-heptanol decreased to 59.3 (13.6\%) (Online resource 4). For this reason, the chemicals were applied every minute during trials. The bees showed a clear preference for marked over non-marked feeders in all treatments (Figure 4). This result indicates a repellent effect of 2-heptanol (in any of its enantiomeric forms). A control experiment showed that bees distributed randomly in both feeders.

\section{DISCUSSION}

We elucidated the structure of the stingless bee Melipona solani pheromone, and we evaluated the 

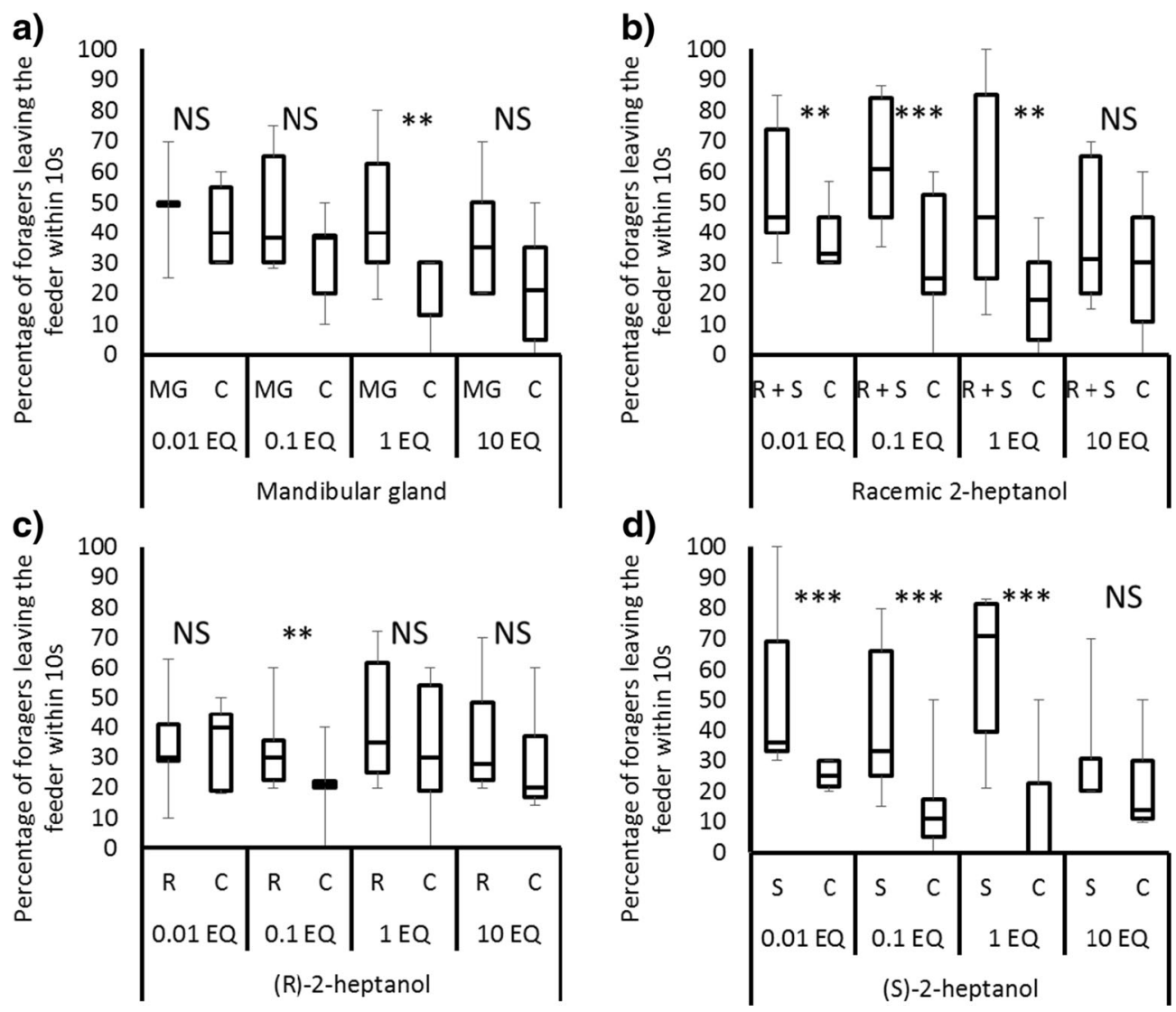

Figure 3. Behavioural responses of Melipona solani workers to four different concentrations of mandibular extract and synthetic 2-heptanol in feeding sites at $30 \mathrm{~m}$ of the colony. a Mandibular gland (M): $0.01 \mathrm{EQ}$ (Kruskal-Wallis $H=1.00, d f=1, P=0.32$ ), 0.1 EQ (Kruskal-Wallis $H=1.70, d f=1, P=0.19$ ), 1 EQ (Kruskal-Wallis $H=6.74$, $d f=1, P<0.01), 10$ EQ (Kruskal-Wallis $H=1.46, d f=1, P=0.23)$. b $(R+S)$-2-heptanol $(R+S): 0.01$ EQ (Kruskal-Wallis $H=5.24, d f=1, P<0.05$ ), 0.1 EQ (Kruskal-Wallis $H=7.32, d f=1, P<0.01$ ), 1 EQ (KruskalWallis $H=5.75, d f=1, P<0.05$ ), 10 EQ (Kruskal-Wallis $H=1.46, d f=1, P=0.23)$. c $(R)$-2-heptanol $(R): 0.01$ EQ (Kruskal-Wallis $H=0.018, d f=1, P=0.89$ ), 0.1 EQ (Kruskal-Wallis $H=4.06, d f=1, P<0.05$ ), 1 EQ (Kruskal-Wallis $H=1.05, d f=1, P=0.31$ ), 10 EQ (Kruskal-Wallis $H=1.06, d f=1, P=0.31$ ). d (S)-2-heptanol $(S)$ : 0.01 EQ (Kruskal-Wallis $H=12.03, d f=1, P<0.001$ ), $0.1 \mathrm{EQ}$ (Kruskal-Wallis $H=8.81, d f=1, P<0.01$ ), 1 EQ (Kruskal-Wallis $H=12.66, d f=1, P<0.001$ ), 10 EQ (Kruskal-Wallis $H=3.40, d f=1, P=0.07$ ). $N=10$ replicates per concentration. ( $* * * P<0.001, * * P<0.01$. $* P<0.05, N S$ not significant).

electroantennogram and behavioural response of the bee to the compound. (S)-2-Heptanol was found to be the only enantiomer in mandibular glands of the bee. This compound was previously reported as the major compound in the alarm pheromone of some stingless bees (Schorkopf 2016) and of other bees of the genus Melipona such as M. fasiata, M. interrupta triplaridis and M. bicolor (GracioliVitti et al. 2004; Cruz-López et al. 2005).
Chiral compounds as secondary alcohols play an important role in alarm pheromone communication (Schorkopf et al. 2009; Schorkopf et al. 2011; Leonhardt 2017). Studies evaluating them have been conducted with some bee species (Patricio et al. 2004). For instance, honey bee workers (Apis mellifera) were able to discriminate between queen- and worker-laid eggs detecting branched hydrocarbon stereoisomers (Katzav- 


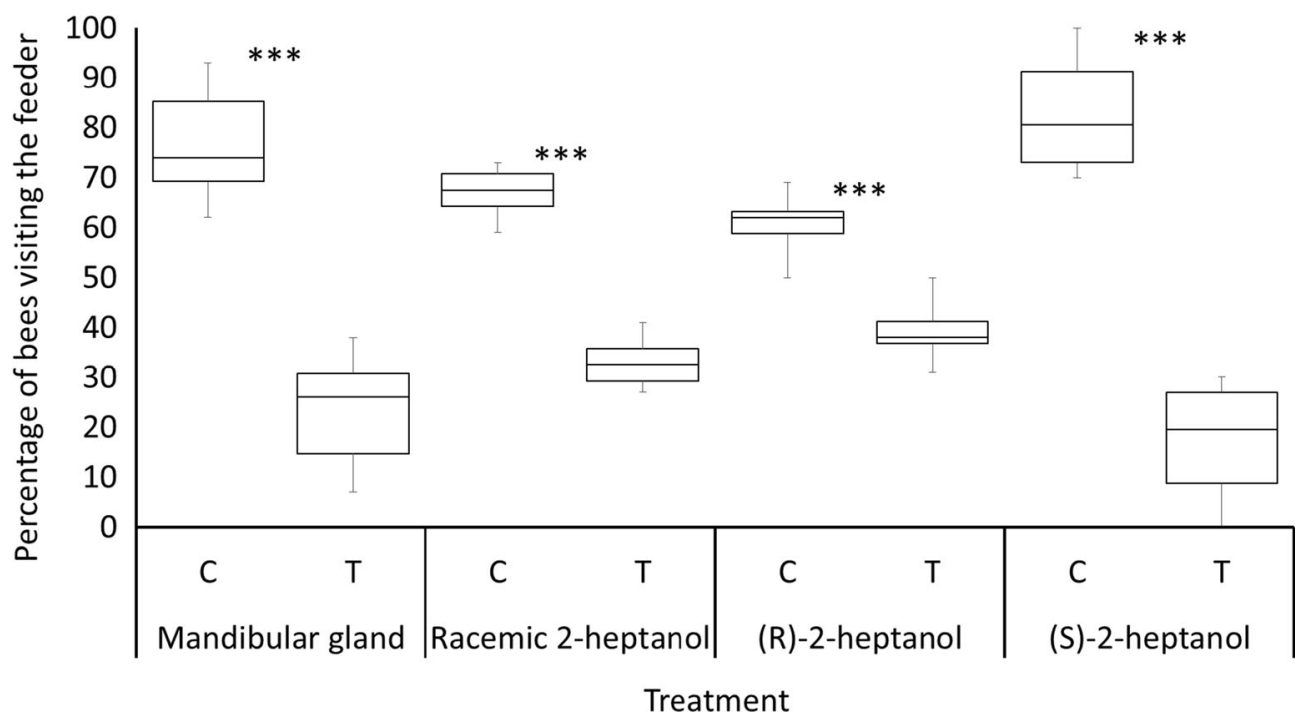

Figure 4. Paired-choice bioassays with mandibular extracts and 2-heptanol. Mandibular gland: (Kruskal-Wallis $H=14.03, d f=1, P<0.001)$. $(R+S)$-2-heptanol: (Kruskal-Wallis $H=14.33, d f=1, P<0.001)$. $(R)$-2-heptanol: (Kruskal-Wallis $H=14.08, d f=1, P<0.001$ ). (S)-2-heptanol: (Kruskal-Wallis $H=14.31, d f=1, P<0.001$ ). $N=$ 10 replicates per treatment. $(* * * P<0.001, * * P<0.01$. $* P<0.05, N S$ not significant).

Gozansky et al. 2003). Andrena wilkella males discriminated enantiomers of cephalic secretions components (Tengo et al. 1990). Also, (-)ipsdienol elicits higher antennal response than (+)-ipsdienol in males of the orchid bee, Euglosa cyanura (Schorkopf et al. 2011). In other insects such as bark beetles, enantiospecific antennal responses to (E)-conophthorin are known (Zhang et al. 2002). The gypsy moth Lymantria dispar discriminated pheromone enantiomers through two binding proteins (Plettner et al. 2000). The cabbage moth Mamestra brassicae discriminates between enantiomers of linalool by olfactory receptor neurons (Ulland et al. 2006).

In a phylogenetic context, $M$. solani belongs to a subgenera Michmelia, and it seems that the production of 2-heptanol is an adaptive trait that bees from multiple subgenera of Melipona evolved (e.g. M. fasiata and M. interrupta triplaridis, from Melikerria, M. bicolor from Eomelipona). It is interesting to note that $M$. beecheii of the subgenus Melikerria does not produce 2-heptanol as a part of its alarm pheromone (Smith and Roubik 1983; Cruz-López et al. 2005; Ramírez et al. 2010). According to the above, more studies with other Melipona species are needed to elucidate the role of phylogeny in alarm pheromone production.

In this study, antennal responses of M. solani to mandibular extract, (S)-2-heptanol, (R)-2heptanol and $(\mathrm{R}+\mathrm{S})-2$-heptanol were dosedependent and not different between them. It is possible that the receptors in the antenna of $M$. solani cannot distinguish optical isomerism. To our knowledge, this is the first work to evaluate enantiomeric alarm pheromone in EAG experiments with a stingless bee. Behavioural responses of the bee to (S)-2-heptanol were higher than responses to (R)-isomer, possibly because, in the context of foraging, bees were more alert to danger. It is also possible that the olfactory system of the bees was more active and selective for compounds because bees occupy this channel to find valuable food resources. This phenomenon was not observed in the EAG experiments likely because we used dissected antennas.

When stingless bees are exposed to alarm pheromones, they either exhibit aggressive behaviour (Johnson and Hubbell 1974) or retreat (Wyatt 2003b). We found that M. solani belongs to the 
"retreating" group. Defensive organisation was dependent on the context, the location and identity of the threat (Breed et al. 2004). Context ranges from threats from large predators (e.g. lizards) to small arthropods (e.g. ants, flies and other bees). As mentioned above, some stingless bees retreat into the colony and close the nest entrance with wax and exhibit docile, timid behaviour (Roubik 2006; Vossler 2012). Studies with Scaptotrigona aff. depilis showed that males respond to alarm pheromone [(S)-(+)-2-heptanol] by flight rather than by fight (Schorkopf 2016), similar to workers of M. solani. For this bee, flight response to any immediate danger, which was observed in workers, may have ensured their survival through time.

In some stingless bees, defence extends to food sources, such as flowers. Colonies maintain territories so that workers from a colony prevent nonnestmate conspecifics from sharing food resources (Breed et al. 2004). Nonetheless, our field bioassays at the feeding sites showed that the response of workers was flying away immediately after the application of the chemicals. The behavioural response of bees to 2-heptanol was enhanced when the feeding site was farther from the colony, especially for the (S)-isomer and the mandibular gland [where the (S)-2-heptanol is stored]. It is possible that bees spend more energy foraging at longer distances, and for that reason, they were more alert and their selectivity to alarm pheromone was reduced.

It is interesting to notice that while 2-heptanol elicits retreat behaviour in M. solani, it provokes attraction in other species (Pianaro et al. 2009). In this scenario, the release of 2-heptanol during competition between $M$. solani and a species that is attracted to 2-heptanol, it would be simply adaptive for both species. In addition, 2-heptanol seems to have other functions. It was found in virgin and physogastric queens of Scaptotrigona mexicana and attracted workers (Grajales-Conesa et al. 2007). Some studies have proposed that mandibular gland compounds serve as markers during food location communication in stingless bees. Most recent studies have demonstrated that mandibular gland compounds are associated to alarm behaviour and that these compounds have a repellent effect on foragers (Schorkopf et al.
2009; Schorkopf 2016). It was argued that the contamination of labial compounds were responsible for the attraction effect observed in pairedchoice experiments of mandibular gland compounds (Jarau et al. 2004; Schorkopf et al. 2009). Due to the high release rate of mandibular compounds (e.g.-2-heptanol), relative to labial compounds (e.g. methyl oleate), the initial response was alarm behaviour but after evaporation of mandibular compounds, attraction due to labial compounds was observed. For that reason, a careful dissection of the mandibular gland was performed and treatments were applied continuously in feeders. Paired-choice bioassays showed that mandibular gland extract, racemic mixture of 2heptanol and both enantiomers were repellent for M. solani foragers, and bees preferred to visit a non-marked feeder.

\section{CONCLUSION}

We found that workers of the stingless bee M. solani released (S)-2-heptanol as an alarm pheromone from their mandibular glands. We also determined that the antennal response of foragers of $M$. solani to mandibular extracts and both isomers of 2-heptanol was dosedependent and on the same scale between treatments. The behavioural response observed was flight and not fight. These compounds, applied at different concentrations, elicited retreat behaviour on exposed bees. High concentrations did not elicit retreat behaviour. Additionally, bees avoided a food source marked with 2-heptanol (both enantiomers and the racemic mixture). Our findings suggested that both enantiomers of 2-heptanol elicited similar antennal responses in M. solani. However, in behavioural evaluations, a stronger response to (S)-2-heptanol was demonstrated. More studies are needed to clarify the situation of effect of the optical isomerism of alarm pheromone perception in Melipona.

\section{ACKNOWLEDGMENTS}

We thank Rodrigo López and Bryan Gómez for assistance in the bioassays work. 


\section{FUNDING INFORMATION}

Thanks are given to the National Council of Science and Technology CONACYT for scholarship to D. A. R. (CV/grant number 387462/255265). This study was supported by CONACYT INFR2014-01(224846).

\section{COMPLIANCE WITH ETHICAL STANDARDS}

Conflict of interest The authors declare that they have no conflict of interest.

(S)-2-Heptanol, phéromone d'alarme de l'abeille sans dard Melipona solani (Hymenoptera, Meliponini)

Phéromone d'alarme / défense / abeilles sans dard / isomérie optique / CG-MS / EAG

(S)-2-Heptanol, das Alarmpheromon der Stachellosen Biene Melipona solani (Hymenoptera, Meliponini)

Alarmpheromon / Verteidigung / Stachellose Bienen / optische Isomerie / CG-MS / EAG

\section{REFERENCES}

Alavez-Rosas D, Malo E, Guzmán M, et al (2017) The stingless bee Melipona solani deposits a signature mixture and methyl oleate to mark valuable food sources. J. Chem. Ecol. 43 :945-954. https://doi. org/10.1007/s10886-017-0886-0

Amano K, Nemoto T, Heard T (2000) What are stingless bees and why and how to use in crop pollination? A review. Jpn. Agric. Res. Q. 34 :183-190.

Ascher J, Pickering J (2017) Discover life: bee species guide and world checklist (Hymenoptera: Apoidea: Anthophila). http://www.discoverlife.org/mp/20q?guide= Apoidea_species\&flags=HAS. Accessed 17 Jul 2017

Ayala R, Gonzalez V, Engel M (2013) Mexican stingless bees (Hymenoptera: Apidae): diversity, distribution, and indigenous knowledge. In: Vit P, Pedro S, Roubik D (eds) Pot-Honey. A legacy of stingless bees, 1 st edn. Springer, New York, pp 135-152

Borg-Karlson AK, Tengö J, Valterová I, et al (2003) (S)(+)-linalool, a mate attractant pheromone component in the bee Colletes cunicularius . J. Chem. Ecol. 29 :114. https://doi.org/10.1023/A:1021964210877

Breed M, Guzmán-Novoa E, Hunt G (2004) Defensive behavior of honey bees: organization, genetics, and comparisons with other bees. Annu. Rev. Entomol. 49 :271-298. https://doi.org/10.1146/annurev. ento.49.061802.123155

Cameron E, Franck P, Oldroyd B (2004) Genetic structure of nest aggregations and drone congregations of the southeast Asian stingless bee Trigona collina. Mol. Ecol. 13 :2357-2364. https://doi.org/10.1111/j.1365294X.2004.02194.X

Cruz-López L, Malo E, Morgan E, et al (2005) Mandibular gland secretion of Melipona beecheii: chemistry and behavior. J. Chem. Ecol. 31 :1621-1632. https://doi. org/10.1007/s10886-005-5802-3

Cruz-López L, Aguilar S, Malo E, et al (2007) Electroantennogram and behavioral responses of workers of the stingless bee Oxytrigona mediorufa to mandibular gland volatiles. Entomol. Exp. Appl. 123 :43-47. https://doi.org/10.1111/j.15707458.2007.00522.x

Gracioli-Vitti L, Abdalla F, Silva R, Jones G (2004) The chemical composition of the mandibular gland secretion of Melipona bicolor Lepeletier, 1836 (Hymenoptera, Apidae, Meliponini): a comparative study among castes and sexes. J. Braz. Chem. Soc. 15:777-781. https://doi.org/10.1590/S0103-50532004000500027.

Grajales-Conesa J, Rojas J, Guzmán-Díaz M, et al (2007) Cephalic and Dufour gland secretions of Scaptotrigona mexicana queens: chemical composition and biological activity. Apidologie 38:38-46. https://doi. org/10.1051/apido:2006052

Jarau S, Hrncir M, Zucchi R, Barth F (2004) A stingless bee uses labial gland secretions for scent trail communication (Trigona recursa Smith 1863). J. Comp. Physiol. A. $190: 233-239$. https://doi.org/10.1007/s00359-0030489-9

Johnson L, Hubbell S (1974) Aggression and competition among stingless bees: field studies. Ecology 55 :120127. https://doi.org/10.2307/1934624

Johnson L, Wiemer D (1982) Nerol: An alarm substance of the stingless bee, Trigona fulviventris (Hymenoptera: Apidae). J. Chem. Ecol. 8:1167-1181. https://doi. org/10.1007/BF00990750

Johnson L, Haynes L, Carlson M, et al (1985) Alarm substances of the stingless bee, Trigona silvestriana. J. Chem. Ecol. $11: 409-416$. https://doi.org/10.1007 /BF00989552

Katzav-Gozansky T, Soroker V, Kamer J, et al (2003) Ultrastructural and chemical characterization of egg surface of honeybee worker and queen-laid eggs. Chemoecology $13: 129-134$. https://doi.org/10.1007 /s00049-003-0238-0

Leonhardt S (2017) Chemical ecology of stingless bees. J. Chem. Ecol. 43 :385-402. https://doi.org/10.1007 /s10886-017-0837-9

Luby J, Regnier F, Clarke E, et al (1973) Volatile cephalic substances of the stingless bees, Trigona mexicana and Trigona pectoralis. J. Insect Physiol. 19:11111127. https://doi.org/10.1016/0022-1910(73)90036-X

Malo E, Castrejón-Gómez V, Cruz-López L, Rojas JC (2004) Antennal sensilla and electrophysiological 
response of male and female Spodoptera frugiperda (Lepidoptera: Noctuidae) to conspecific sex pheromone and plant odors. Ann. Entomol. Soc. Am. $97: 1273-1284$. https://doi.org/10.1603/00138746(2004)097[1273:ASAERO]2.0.CO;2

Meléndez-Ramirez V, Meneses-Calvillo L, Kevan P (2013) Effects of human disturbance and habitat fragmentation on stingless bees. In: Vit P, Pedro S, Roubik D (eds) Pot honey: a legacy of stingless bees, 1 st edn. Springer, New York, pp 269-282

Michener C (2007) The bees of the world, 2nd edn. The Johns Hoptkins University Press, Baltimore

Michener C (2013) The Meliponini. In: Vit P, Silva P, Roubik D (eds) Pot honey: a legacy of stingless bees, 1st edn. Springer-Verlag, New York, pp 3-17

Mori K (1998) Chirality and insect pheromones. Chirality $10: 578-586$. https://doi.org/10.1002/(SICI)1520-636 X(1998)10:7<578::AID-CHIR5>3.0.CO;2-Z

Mori K (2014) Stereochemical studies on pheromonal communications. Proc. Jpn. Acad. Ser. B Phys. Biol. Sci. $90: 373-388$. https://doi.org/10.2183/pjab.90.373

Patricio E, Cruz-López L, Morgan E (2004) Electroantennography in the study of two stingless bee species (Hymenoptera: Meliponini). Braz. J. Biol. 64 :827-31. https://doi.org/10.1590/S151969842004000500012

Pianaro A, Menezes C, Kerr W, et al (2009) Stingless bees: Chemical differences and potential functions in Nannotrigona testaceicornis and Plebeia droryana males and workers. J. Chem. Ecol. 35:1117-1128. https://doi.org/10.1007/s10886-009-9679-4

Plettner E, Lazar J, Prestwich E, Prestwich G (2000) Discrimination of pheromone enantiomers by two pheromone binding proteins from the gypsy moth Lymantria dispar. Biochemistry $39: 8953-8962$. https://doi. org/10.1021/bi000461x

R Core Team (2016) R: A language and environment for statistical computing

Ramírez S, Nieh J, Quental T, et al (2010) A molecular phylogeny of the stingless bee genus Melipona (Hymenoptera: Apidae). Mol. Phylogenet. Evol. 56 :519525. https://doi.org/10.1016/j.ympev.2010.04.026

Rochat D, Ramirez-Lucas P, Malosse C, et al (2000) Role of solid-phase microextraction in the identification of highly volatile pheromones of two Rhinoceros beetles Scapanes australis and Strategus aloeus (Coleoptera, Scarabaeidae, Dynastinae). J. Chromatogr. A 885 :433-444. https://doi.org/10.1039/c1cc00005e

Roubik D (2006) Stingless bee nesting biology. Apidologie 37 :124-143. https://doi.org/10.1051/apido:2006026

Schorkopf D (2016) Male meliponine bees (Scaptotrigona aff. depilis) produce alarm pheromones to which workers respond with fight and males with flight. J. Comp. Physiol. A. $202: 667-678$. https://doi. org/10.1007/s00359-016-1109-9
Schorkopf D, Hrncir M, Mateus S, et al (2009) Mandibular gland secretions of meliponine worker bees: further evidence for their role in interspecific and intraspecific defence and aggression and against their role in food source signalling. J. Exp. Biol. 212:1153-1162. https://doi.org/10.1242/jeb.021113

Schorkopf D, Mitko L, Eltz T (2011) Enantioselective preference and high antennal sensitivity for (-)ipsdienol in scent-collecting male orchid bees, Euglossa cyanura. J. Chem. Ecol. 37:953-960. https://doi.org/10.1007/s10886-011-0010-9

Slessor K, Kaminski L, King G, Winston M (1990) Semiochemicals of the honeybee queen mandibular glands. J. Chem. Ecol. 16:851-860. https://doi.org/10.1007 /BF01016495

Smith B, Roubik D (1983) Mandibular gland of stingless bees (Hymenoptera: Apidae): chemical analysis of their contents and biological function in two species of Melipona . J. Chem. Ecol. 9 :1465-1472. https://doi. org/10.1007/BF00988512

Strohalm H, Dregus M, Wahl A, Engel K (2007) Enantioselective analysis of secondary alcohols and their esters in purple and yellow passion fruits. J. Agric. Food Chem. 55 :10339-10344. https://doi. org/10.1021/jf072464n

Tengo J, Agren L, Baur B, et al (1990) Andrena wilkella male bees discriminate between enantiomers of cephalic secretion components. J. Chem. Ecol. 16:429-441. https://doi.org/10.1007/BF01021775

Ulland S, Ian E, Borg-Karlson A, Mustaparta H (2006) Discrimination between enantiomers of linalool by olfactory receptor neurons in the cabbage moth Mamestra brassicae (L.). Chem. Senses 31:325334. https://doi.org/10.1093/chemse/bjj036

Vossler F (2012) Flower visits, nesting and nest defence behaviour of stingless bees (Apidae: Meliponini): suitability of the bee species for meliponiculture in the Argentinean Chaco region. Apidologie 43 :139-161. https://doi.org/10.1007/s13592-011-0097-6

Wyatt T (2003a) Pheromones and animal behaviour: communications by smell and taste, First. Cambridge University Press, New York

Wyatt T (2003b) Fight or flight: alarm pheromones. In: Wyatt T (ed) Pheromones and animal behaviour: communications by smell and taste, first. Cambridge University Press, New York, pp 146-163

Zhang Q, Tolasch T, Schlyter F, Francke W (2002) Enantiospecific antennal response of bark beetles to spiroacetal (E)-conophthorin. J. Chem. Ecol. 28:1839-1852. https://doi.org/10.1023 /A: 1020569303433

Publisher's note Springer Nature remains neutral with regard to jurisdictional claims in published maps and institutional affiliations. 